\title{
ACESSIBILIDADE EM AMBIENTES ESCOLARES: IDENTIFICAÇÃO DE BARREIRAS FÍSICAS
}

\section{ACCESSIBILITY IN SCHOOL ENVIRONMENTS: IDENTIFICATION OF PHYSICAL BARRIERS}

\author{
Ana Beatriz Soares Pereira ${ }^{1}$, PIBIC/IFMA \\ Matheus Alberto Menezes Silva², PIBIC/IFMA \\ Ivana Márcia Oliveira Maia ${ }^{3}$, D.Sc. \\ Anselmo Cardoso de Paiva ${ }^{4}$, D.Sc. \\ (1) Instituto Federal de Educação Ciência e Tecnologia do Maranhão \\ e-mail: anabeatriz-pereira@hotmail.com \\ (2) Instituto Federal de Educação Ciência e Tecnologia do Maranhão \\ e-mail:maatheusalbertoo@hotmail.com \\ (3) Instituto Federal de Educação Ciência e Tecnologia do Maranhão \\ e-mail:ivana.maia@ifma.edu.br \\ (4) Universidade Federal do Maranhão \\ e-mail: anselmo.c.paiva@gmail.com
}

Palavras chave: acessibilidade, inclusão escolar, design universal.

Este trabalho é resultado parcial de pesquisa para definição de ambiente escolar apropriado para educação inclusiva desenvolvido em projeto de Iniciação Científica em Nível Médio. Neste artigo, são identificadas as armadilhas de acessibilidade escolar que funcionam como barreiras físicas, algumas vezes quase imperceptíveis, que dificultam o acesso e utilização de ambientes por pessoas com alguma deficiência física, como os desníveis de piso, maçanetas, portas, janelas, interruptores, bebedouros, sanitários, válvulas de descarga, torneiras, lavatórios e papeleiras. O estudo possibilitou identificar os variados modelos desses elementos utilizados em escolas públicas e particulares, além de apontar os modelos mais adequados para a escola inclusiva. A metodologia adotada é pesquisa por observação direta, seguida de revisão bibliográfica e análise qualitativa, baseada em evidências científicas consistentes sobre a usabilidade dos elementos físicos comuns aos ambientes escolares.

\section{Keywords: Accessibility, school inclusion, universal design.}

Abstract: This paper presents partial result of research to appropriate school environment for inclusive education developed in the project of Scientific Initiation in Middle Level. Thus the school accessibility traps are identified that act as physical barriers, sometimes almost imperceptible, that hinder access and use of environments by people with physical disabilities, such as floor differences, doorknobs, doors, windows, switches, drinking fountains, toilets, flushing valves, taps, sinks and paper wafers. The study enables to identify the varied models of these elements used in public and private schools, in addition to pointing out the most suitable models for the inclusive school. The

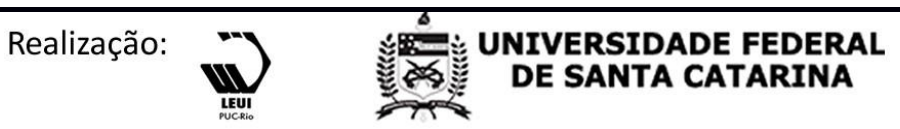


$16^{\circ}$ USIHC - Congresso Internacional de Ergonomia e Usabilidade de Interfaces Humano Computador

CINAHPA | 2017 - Congresso Internacional de Ambientes Hipermídia para Aprendizagem.

methodology is research by direct observation, followed by bibliographic review and qualitative analysis, based on consistent scientific evidence about the usability of physical elements common to school environments.

\section{Introdução}

Sabe-se que no Brasil, cerca de $23,9 \%$ da população possui um tipo de deficiência (IBGE, 2010), e o Censo Escolar do ano de 2015, afirmou que aproximadamente 698.768 estudantes com algum tipo de limitação física ou cognitiva foram matriculados em classes comuns de educação básica no ano de 2014 e a Declaração Universal dos Direitos Humanos da Organização das Nações Unidas (ONU, 1948), afirma que "Todo ser humano tem direito à liberdade de locomoção". Neste contexto, a estrutura do ambiente com acessibilidade tornase de extrema importância para fornecer uma educação inclusiva, tornando o ambiente acessível para pessoas com limitações ou sem, de forma que, facilite o uso diário dos elementos físicos presentes. Nestas circunstâncias, o projeto reconhece de forma ergonômica as barreiras físicas que se encontram nos itens essenciais do âmbito escolar, que são aqueles que dificultam ou impossibilitam o acesso por pessoas.

Este trabalho é resultado parcial de pesquisa para definição de ambiente escolar apropriado para educação inclusiva. Neste artigo, são identificadas as armadilhas de acessibilidade escolar que funcionam como barreiras físicas, por vezes quase imperceptíveis, que dificultam o acesso e utilização de ambientes por pessoas com deficiência (PcD), como os desníveis de piso, maçanetas, portas, janelas, interruptores, bebedouros, sanitários, válvulas de descarga, torneiras, lavatórios e papeleiras. A pesquisa permitiu apontar quais os tipos mais utilizados, a sua forma de usualidade e destacar o modelo mais adequado de cada categoria, com o auxílio da Associação Brasileira de Normas Técnicas, para que seja possível contribuir para o bem-estar de todos que os utilizam e contribuir com a inclusão social na escola.

\section{Objetivo}

Os objetivos deste trabalho visam contribuir para a inclusão social de PcD, aperfeiçoando a interação homem ambiente, de forma a contribuir com o conforto, segurança e eficiência na realização das suas atividades da vida diária (AVDs) sem caráter discriminativo ou excludente. $\mathrm{O}$ objetivo geral está relacionado à contribuição para a autonomia de todos os frequentadores do ambiente, ao identificar as armadilhas que dificultam ou impossibilitam que uma pessoa possa desfrutar de todos os ambientes, sem restrições. A meta é contribuir na inclusão social, identificando as barreiras físicas identificadas como armadilhas de acessibilidade que estão presentes nos espaços comuns à maioria das escolas, tais como salas de aula, banheiros, bibliotecas, sala de estudo, sala de reunião, escritório, corredores, lanchonete, laboratório, área de convivência e auditório. Neste trabalho são apontados os tipos de elementos mais utilizados, sua usabilidade e o modelo mais adequado de cada elemento.

\section{Metodologia}

Este trabalho é uma revisão bibliográfica sistemática, interpretativa, ancorada em análise qualitativa, baseada em evidências científicas consistentes sobre a usabilidade dos elementos físicos comuns aos ambientes escolares. Foram realizados estudos, para que fosse possível identificar e avaliar ergonomicamente cada elemento tido como barreira física. Os estudos sobre a usabilidade de cada elemento possibilitaram definir com base na ABNT, o 
 CINAHPA}

modelo mais adequado para ser usado em ambientes de forma a contribuir com o bemestar de todos os envolvidos na educação inclusiva.

\section{Resultados}

Segundo Marina Pezzini (2013) o design deve, entre outras coisas, comunicar mais, fornecer uma experiência de uso completa, além de ser funcional e usável, deve estabelecer uma conexão com o usuário que gere afeto. Nesse contexto, foram observados os elementos essenciais comuns aos ambientes escolares e a sua possível interação com pessoas com limitação física.

\subsection{Maçanetas}

A utilização de maçanetas depende do manejo, ou seja, da sua forma própria de controle. Segundo Iida (2016) de forma geral, há dois tipos básicos: manejo fino ou de precisão, executado pelas pontas dos dedos, que se classificam em três formas de analogia: digital, tenaz e lateral. Há o manejo grosseiro ou de força, executado com o centro da mão, suas três formas de classificação de analogia são: o gancho, a esférica e o anel. $\mathrm{O}$ tipo de manejo fino é o utilizado em maçanetas, pois sua utilização requer apenas precisão, não necessitando de forças maiores, nem velocidade. Entre os três modelos identificados na pesquisa, percebe-se que o de alavanca (Fig. 1c) é o mais adequado, visto que não há necessidade de pega, não exige firmeza, torção do pulso e precisão em seu acionamento, ao contrário, dos modelos, oval e bola (Fig. 1a e 1b) os quais exigem que o usuário tenha força, torção e precisão das mãos e dedos, impossibilitando serem acionados por pessoas com deficiência motora ou que estejam com mãos ocupadas. Para que maçaneta do tipo alavanca seja utilizada de forma correta, deve-se seguir as normas regidas pela Associação Brasileira de Normas Técnicas (ABNT), encontradas na NBR 9050:2015, a qual afirma $16^{\circ}$ Ergodesign - Congresso Internacional de Ergonomia e Usabilidade de Interfaces Humano Tecnológica: Produto, Informações Ambientes Construídos e Transporte

$16^{\circ}$ USIHC - Congresso Internacional de Ergonomia e Usabilidade de Interfaces Humano Computador

CINAHPA | 2017 - Congresso Internacional de Ambientes Hipermídia para Aprendizagem.

que a maçaneta deve possuir no mínimo $0,10 \mathrm{~m}$ de comprimento, com acabamento sem arestas e recurvado na extremidade, com uma distância mínima de $4 \mathrm{~cm}$ da superfície da porta, ser instalada a uma altura entre $0,80 \mathrm{~m}$ e $1,10 \mathrm{~m}$ do pisco acabado.

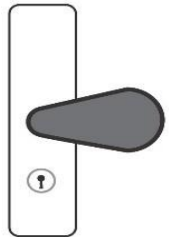

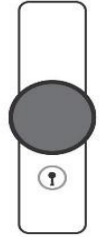

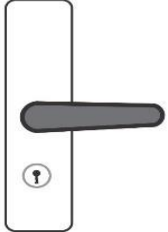

Figura 1. Tipos de maçanetas mais utilizadas em escolas

\subsection{Portas}

Entre todos os modelos, a porta automática (Fig.2 d) é a mais recomendada e apropriada por conta de seu benefício de não se fazer uso de membros superiores e inferiores para ser acionada, porém seu custo não é acessível, tornando a porta de uma folha (Fig. 2b e 2c) a mais adequada de acordo com custo/benefício, mas para que seja utilizada no ambiente escolar deve-se seguir as normas estabelecidas pela ABNT NBR 9050:2015, a qual estabelece que, a porta quando aberta deve possuir um vão livre, de no mínimo 0,90 $\mathrm{m}$ de largura e 2,10 $\mathrm{m}$ de altura, possuir condição de ser aberta com um único movimento, conter na parte inferior da folha da porta um revestimento resistente a impactos provocados por bengalas, muletas e cadeiras de rodas, numa altura de $0,40 \mathrm{~m}$ a partir do piso. Também se faz necessário a preservação de um espaço lateral para que pessoas em cadeiras de rodas ou andadores, possam movimentar as maçanetas, tendo condições de abrirem facilmente as portas.

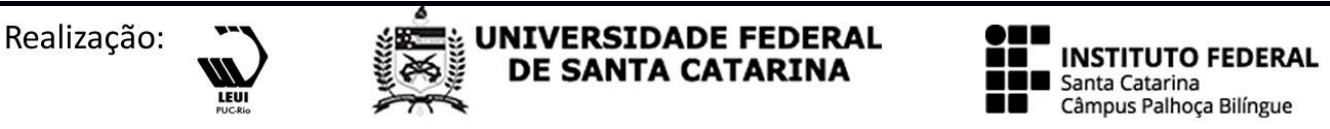




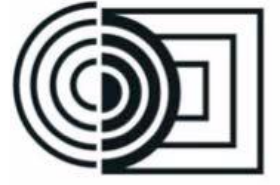
CINAHPA

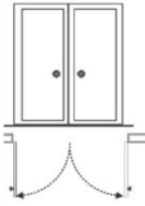

a

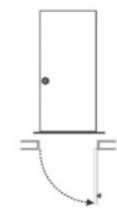

b

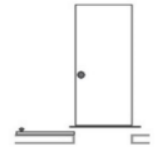

c

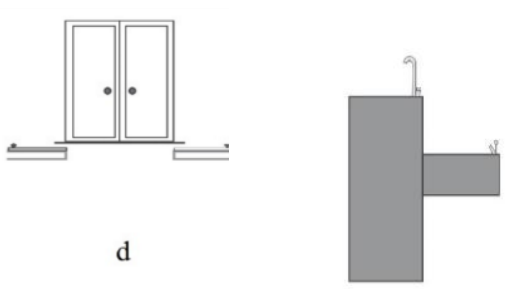

a

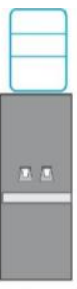

b

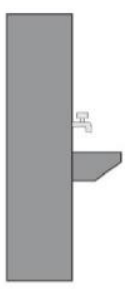

c

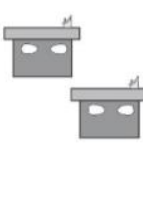

d
Para o banheiro, é necessário um puxador horizontal no lado oposto ao lado da abertura da porta, de forma que fique associado à maçaneta. Deve estar a uma distância de $0,10 \mathrm{~m}$ do eixo da porta com comprimento mínimo de $0,40 \mathrm{~m}$, com diâmetro variando de $35 \mathrm{~mm}$ a $25 \mathrm{~mm}$, com uma instalação a $0,90 \mathrm{~m}$ do piso.

\subsection{Bebedouros}

Entre os modelos observados na pesquisa não é considerada a utilização por pessoas sem os membros superiores, por isso foi observado que o modelo mais adequado é o bebedouro de pressão (Fig. 3a e 3d), pois possui todos os elementos necessários para ser utilizado por todos os usuários que possuem membros superiores, mas necessitam seguir as normas especificadas na ABNT NBR 9050:2015, que afirma que, a bica no bebedouro deve ser do tipo de jato inclinada, estar localizada no lado frontal do bebedouro, permitir a utilização por meio de copos e ser de fácil higienização, deve-se instalar bebedouros com no mínimo duas alturas deferentes de bica, sendo uma de $0,90 \mathrm{~m}$ e outra $1,00 \mathrm{~m}$ em relação piso acabado, é informado que, deve possuir altura livre de no mínimo 0,73 $\mathrm{m}$ do piso, garantindo um módulo de referência (M.R. $1,20 \mathrm{~m} \times 0,80 \mathrm{~m}$ ) para a aproximação frontal ao bebedouro, podendo avançar sob o bebedouro até no máximo $0,50 \mathrm{~m}$, no caso de usuário de cadeira de rodas. Esses modelos são os acessíveis e adequados para o âmbito escolar. Os modelos 3 b e 3c, não são apropriados, porque eles precisam do uso de copos ou de manuseio de torneiras.
Figura 3. Tipos de bebedouros mais utilizados no ambiente escolar.

\subsection{Interruptores}

Entre os seis modelos mais utilizados de interruptores, pode-se recomendar o sensor de presença como o mais adequado, devido seus benefícios de não necessitar utilizar membros superiores para acioná-lo e por serem sustentáveis, entre outros fatores. Entretanto, visando o custo benefício, o interruptor simples de uma seção (Fig. 4a) é o mais adequado, ficando como segunda opção, podendo ser acionado apenas por um leve toque sem necessidade de uma força, torção e precisão. Interruptores com duas ou mais seções (Fig.4b e $4 c)$ dificultam a sua usabilidade, por conta da proximidade entre suas teclas/botões. Segundo a ABNT 9050:2015, a altura dos interruptores deve ser entre $0,60 \mathrm{~m}$ a 1,00 $\mathrm{m}$ do piso acabado.

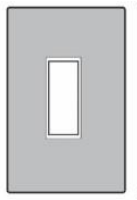

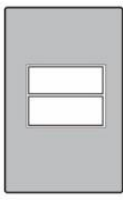

b

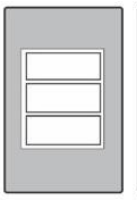

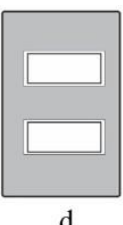

d
Figura 4. Tipos de interruptores mais utilizados nos ambientes escolares.

\subsection{Janelas}

Conhecendo a diversidade de materiais com os quais as janelas são executadas, como madeira, ferro, alumínio e PVC, e diversos modelos de janelas, é necessário respeitar alguns critérios, entre eles, segurança, durabilidade, manutenção, aspectos econômicos, além de, considerar 


\section{$16^{\circ}$ \\ ERGODESIGN USIHC CINAHPA}

limites de alcance visual, na altura mínima de $0,60 \mathrm{~m}$ para que pessoas que necessitam utilizar cadeira de rodas possam visualizar o ambiente externo e também possam operar cada folha ou módulo da janela com um único movimento, utilizando apenas uma mão. Visando o custo benefício, local a serem utilizadas e os critérios estabelecidos, foi observado que o modelo mais adequado é: a janela de correr, feita de vidro ou alumínio, devido sua durabilidade, fácil utilização e em relação à segurança não ocupa espaço interno e externo, desta forma, não ocupa o ambiente de circulação, não necessitando de esforço em seu manuseio, pois é leve e pode ser aberta facilmente com uma mão. Seu puxador deve ser do tipo alavanca, por conta de sua praticidade e respeitar a altura entre $0,60 \mathrm{~m}$ a 1,20 m, estabelecida na ABNT NBR 9050:2015. Por questões estruturais, exigência de força excessiva durante o manuseio e custos, os outros modelos existentes não são recomendados, de acordo com a ABNT NBR 9050:2004.

\subsection{Papeleiras}

Entre os dois modelos mais utilizados, embutidas e não embutidas, ambos são recomendados, desde que sigam as regras estabelecias pela ABNT NBR 9050:2015, as papeleiras embutidas ou que avancem no máximo $0,10 \mathrm{~m}$ da parede: necessitam estar instaladas a uma altura de $0,50 \mathrm{~m}$ a $0,60 \mathrm{~m}$ do chão, com uma distância de $0,15 \mathrm{~m}$ da borda frontal da bacia sanitária e as papeleiras não embutidas: é obrigatório estarem alinhadas com a parte frontal da bacia sanitária. Para o acesso ao papel deve ser fixada entre $1,00 \mathrm{~m}$ e $1,20 \mathrm{~m}$ do chão.

\subsection{Lavatórios e torneiras}

Para que todos possam utilizar a torneira com

total facilidade, é recomendável que elas sejam do modelo automático, acionadas por sensor. $16^{\circ}$ Ergodesign - Congresso Internacional de Ergonomia e Usabilidade de Interfaces Humano Tecnológica: Produto, Informações Ambientes Construídos e Transporte

$16^{\circ}$ USIHC - Congresso Internacional de Ergonomia e Usabilidade de Interfaces Humano Computador

CINAHPA | 2017 - Congresso Internacional de Ambientes Hipermídia para Aprendizagem.

Entretanto, o custo desse artefato está acima do recurso comumente aplicado na construção de escolas, fazendo com que o modelo de torneira acionada por alavanca seja o mais recomendado, desde que não necessite de extrema força e que esteja situada $0,50 \mathrm{~m}$ da parte frontal do lavatório, o qual deve ser suspenso numa altura mínima de $0,73 \mathrm{~m}$, não podendo ser do tipo coluna.

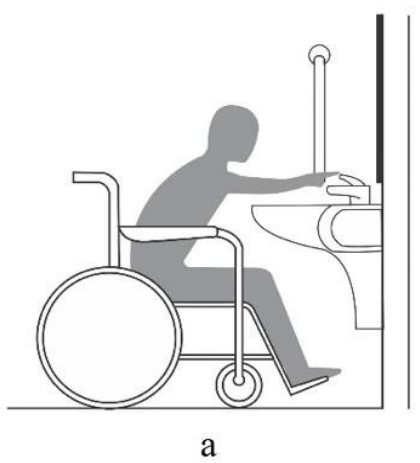

Figura 5. Modelo de lavatório com torneira alavanca.

Deve possuir barras de apoio nas paredes laterais dos lavatórios nas extremidades, o sifão e a tubulação devem estar a uma distância mínima de $0,25 \mathrm{~m}$ da face externa frontal e devem possuir protetores. Os outros modelos existentes não são recomendados, pois requerem força do usuário.

\subsection{Tomadas}

Seguindo as normas da ABNT NBR 9050:2015, deve-se seguir que a altura correta para tomadas é entre $0,40 \mathrm{~m}$ a $1,00 \mathrm{~m}$ do pisco acabado, para que fique acessível para todos. O modelo adequado para o ambiente escolar, segundo a ABNT NBR 13570/1996 são as tomadas com uma entrada para que em sua utilização não fique sobrecarregada, possuem proteção contra contato direto, seus contatos elétricos internos estão aprofundados em relação à superfície, há uma elevação na lateral para que não haja contato dos dedos com o pino, evitando os choques elétricos.

\section{Realização:

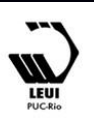




\section{$16^{\circ}$ \\ ERGODESIGN USIHC CINAHPA}

\subsection{Bacia sanitária}

Entre os três modelos disponíveis e recomendados para o ambiente escolar, o mais adequado por conta da acessibilidade é a bacia sanitária sem caixa acoplada. Para que não atrapalhe o usuário de cadeira de rodas, a bacia deve conter assento, com abertura frontal, devem estar a uma altura entre $0,43 \mathrm{~m}$ e $0,45 \mathrm{~m}$ do piso acabado (medidas com início na borda superior sem o assento, até o piso acabado), se a medida for com assento o limite máximo é 0,46 $\mathrm{m}$. Os outros modelos atrapalham o acesso por usuários que utilizam cadeira de rodas ou andadores.

\subsection{Acionadores ou válvulas de descarga.}

Entre os 3 modelos de acionadores ou válvulas de descarga, o mais adequado de acordo com a ABNT 9050:2015 é a válvula de descarga do modelo sensor. Entretanto o custo elevado dessa solução pode inviabilizar seu uso em ambientes escolares. O modelo alavanca (Fig. 6c) apresenta boa adequação. Com baixo custo e fornecendo praticamente os mesmos benefícios, a alavanca não exige força para ser acionada $\mathrm{e}$ deve estar a uma altura máxima de $1,00 \mathrm{~m}$ do piso acabado. Os modelos de válvulas de pressão (Fig. 6b) e de caixa de descarga elevada (Fig. 6a) não são recomendados pois requerem empunhadura e força do usuário.

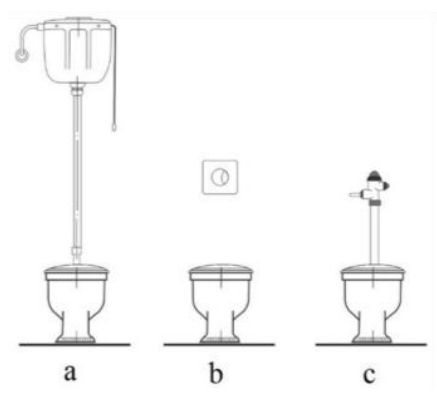

Figura 6 - Modelo de acionadores ou válvulas de descarga mais utilizadas. $16^{\circ}$ Ergodesign - Congresso Internacional de Ergonomia e Usabilidade de Interfaces Humano Tecnológica: Produto, Informações Ambientes Construídos e Transporte

$16^{\circ}$ USIHC - Congresso Internacional de Ergonomia e Usabilidade de Interfaces Humano Computador

CINAHPA | 2017 - Congresso Internacional de Ambientes Hipermídia para Aprendizagem.

\subsection{Desníveis de piso}

Segundo a ABNT 9050:2015, o ideal seria o ambiente não possuir desníveis de piso devido ao tráfego de pessoas com deficiências físicas, porém, irregularidades de até $5 \mathrm{~mm}$ podem ser ignoradas; superiores a $5 \mathrm{~mm}$ e até $15 \mathrm{~mm}$ é necessário que sejam tratados como rampa com inclinação máxima de 50\%; superiores a $15 \mathrm{~mm}$ sejam tratados como degraus e possuírem rampas.

\section{Discussão}

Tornar um ambiente acessível é de suma importância, visto que em 2010 foi informado pelo Instituto Brasileiro de Geografia e Estatística no Censo de 2010 que cerca de, 45,6 milhões de pessoas afirmam que possuem ao menos um tipo de deficiência, o que equivale a $23,9 \%$ da população brasileira. De acordo com o Censo Escolar de 2015, cerca de 698.768 são estudantes, esses números intensificam e justificam ainda mais a importância de se ter um ambiente escolar acessível para receber a todos os seus frequentadores, respeitando os direitos estabelecidos pela Declaração Universal dos Direitos Humanos da Organização das Nações Unidas (ONU, 1948). Um ambiente acessível é aquele que possibilita acolher a todos. O que cria uma sociedade inclusiva, é o conjunto de ações que favorecem uma integração social global. Dessa forma, organizar e caracterizar o ambiente físico é apenas um aspecto dessa iniciativa, mas deve estar além criação de rampas e barras, é necessária atenção aos detalhes.

\section{Conclusão}

A acessibilidade é um direito garantido por lei no Brasil, no entanto, muito ainda deve ser feito para que pessoas com deficiências físicas possam ter trânsito livre e realizar suas atividades sem 


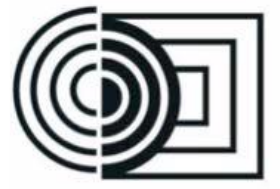

constrangimentos de execução. Este trabalho visa contribuir de forma significativa para a qualidade dos ambientes escolares inclusivos e que todas as atividades possam ser realizadas, proporcionando conforto, satisfação e segurança aos usuários.

É importante projetar um ambiente que possa receber a todos, favorecendo para a independência de cada cidadão, motivando uma sociedade que compreende e respeita as diferenças de todos. O mérito científico deste projeto é a identificação de armadilhas quase imperceptíveis em ambientes comuns em uma escola, sugerindo mudanças na estrutura física para possibilitar a independência do frequentador do ambiente independentemente se ter ou não deficiências.

\section{Referências}

IBGE, Censo Demográfico 2010:

Características gerais da população, religião e pessoas com deficiência. Acessado em http://www.ibge.gov.br/home/estatistica/populaa o/censo2010/caracteristicas_religiao_deficie ncia/caracteristicas_religiao_deficiencia_tab_p df.shtm

Portal Brasil, Educação: dados do censo escolar indicam aumento de matrículas de alunas com deficiência. Acessado em:

http://www.brasil.gov.br/educacao/2015/03/dad os-do-censo-escolar-indicam-aumento-

dematriculas-de-alunos-com-deficiencia

SASSAKI, Romeu Kazumi. Inclusão: acessibilidade no lazer, trabalho e educação.

Revista Nacional de Reabilitação (Reação), São

Paulo, Ano XII, mar./abr. 2009, p. 10-16. $16^{\circ}$ Ergodesign - Congresso Internacional de Ergonomia e Usabilidade de Interfaces Humano Tecnológica: Produto, Informações Ambientes Construídos e Transporte

$16^{\circ}$ USIHC - Congresso Internacional de Ergonomia e Usabilidade de Interfaces Humano Computador

CINAHPA | 2017 - Congresso Internacional de Ambientes Hipermídia para Aprendizagem.

Norma Brasileira: ABNT 9050, Acessibilidade a edificações, mobiliário, espaços e equipamentos urbanos. 3.ed. Rio de Janeiro: [s.n.],2015. 148 p.

GUIA Prático de Acessibilidade: Critérios e especificações técnicas para avaliação de acessibilidade em edificações, mobiliário e espaços. [S.l.: s.n.], [21--?]. 142 p. Disponível em: <http://www.mpsp.mp.br/portal/page/porta 1/Cartilhas/GuiaPraticoDeAcessibilidade.pdf $>$. Acesso em: 01 fev. 2017.

IIDA, Itiro; BUARQUE, Lia. Ergonomia: projeto e produção. 3. ed. São Paulo: Blucher, 2016. $850 \mathrm{p}$.

PEZZINI, M. Design emocional: curso: design, disciplina: Ergonomia 3 - UFSC. Notas de Aula. Slides. 2013. Disponível em:

<http://www.slideshare.net/marinapzn/apost ilade-design-2013>. Acesso em: mar/17.

\section{Agradecimentos}

Ao DRG E PRPGI do Instituto Federal de Educação, Ciência e Tecnologia do Maranhão Campus São Luis Monte Castelo.

Ao CNPq e FAPEMA, pelo apoio educacional e financeiro.

\section{Realização: "-) UNIVERSIDADE FEDERAL

